Revista de Derecho

\title{
Protección jurídica de las artes escénicas y sus elementos creativos
}

Legal protection of scenic arts and their creative elements

\author{
Karina Larrea \\ Instituto Superior de Derecho y Economía de Madrid \\ klarrea16@gmail.com
}

DOI: https://doi.org/10.32719/26312484.2019.31.7

Fecha de recepción: 2 de abril de 2018

Fecha de aprobación: 26 de febrero de 2019 


\section{RESUMEN}

La normativa actual sobre derechos de autor en Ecuador protege el guion de teatro, las obras dramáticas o teatrales, las coreografías y pantomimas. Por otro lado, los derechos conexos protegen las actuaciones del artista, intérprete o ejecutante de una obra previamente existente. Sin embargo, quienes hayamos asistido alguna vez como espectadores a alguna obra teatral, ópera, espectáculo circense, ballet, etc., sabemos que la obra escénica bien puede apreciarse como un todo, es decir, como un solo espectáculo, pero también como un conjunto de elementos con un menor o mayor grado de creatividad que merecen una protección suficiente. Las normas jurídicas nacionales, comunitarias e internacionales brindan diferentes formas y niveles de protección a los titulares de derechos de autor y derechos conexos en la medida en que sus obras (en el caso de los autores) o sus actuaciones e interpretaciones (en el caso de los artistas, intérpretes o ejecutantes) sean originales o alcancen un alto nivel de creatividad. El presente ensayo pretende entonces identificar la legislación aplicable a las artes escénicas y sus elementos creativos en Ecuador y el alcance de su protección.

PalABRAS Clave: artes escénicas, autor, obra, derecho de autor, derechos conexos, artista, intérprete, ejecutante, elementos creativos, titular de derechos, requisitos de protección, protección jurídica.

\section{ABSTRACT}

In Ecuador, the current regulations on copyright protect the theater scripts, dramatic or theatrical works, choreographies and pantomimes. On the other hand, neighboring rights protect the performances of the artist and performers of a previously existing work. However, those of us who have ever attended as spectators to some theatrical work, opera, circus show, ballet, etc. know that the scenic work can be seen as a whole, in other words, as a single spectacle, but also as a set of elements with a lesser or greater degree of creativity that deserve sufficient protection. National, community and international legal norms provide different forms and levels of protection to holders of copyright and related rights if their works (in the case of authors) or their actions and interpretations (in the case of artists or performers) are original or reach a high level of creativity. The present essay intends to identify the applicable legislation to the scenic arts and their creative elements in Ecuador as well as the scope of their protection.

KEYWORDs: Performing arts, author, piece, copyright, related rights, artist, performer, creative elements, rights holder, protection requirements, legal protection. 


\section{INTRODUCCIÓN}

Tas artes escénicas existen desde que el ser humano fue capaz de emplear su cuerpo como una forma de expresión, incluso antes del lenguaje, el movimiento corporal y la gesticulación facial. Además de ser un motor de cambio social, constituyen un espacio ideal de expresión, creación y transmisión de las emociones y el pensamiento humanos, por lo que vale la pena su protección y fomento.

Podemos entender a las artes escénicas como toda manifestación artística materializada en un espacio escénico, sea este especialmente diseñado para ello (sala de teatro o centro de espectáculos), o cualquier otro espacio que permita su ejecución y expresión (espacios públicos en la ciudad, escuelas, etc.). Al pensar en artes escénicas, es habitual que lo primero que se nos venga a la mente sea la actividad teatral, sin embargo, comprenden también la danza y la música, pudiendo muchas veces estas tres fusionarse en un mismo espectáculo. De las artes escénicas derivan la ópera, conciertos y festivales, el circo, carnavales, desfiles y otras manifestaciones populares o tradicionales.

A diferencia de otras disciplinas artísticas, en las cuales basta el trabajo del creador de forma unipersonal, como por ejemplo la literatura, la pintura o la fotografía, las artes escénicas requieren indispensablemente de un trabajo común entre todos sus participantes. Director, autor dramático, actores, escenógrafo, coreógrafo, director de vestuario, iluminador; entre otros, fusionan sus conocimientos y creatividad para dar nacimiento a la obra escénica y presentarla al público. De allí que la protección de las artes escénicas requiera un análisis particular y un tratamiento especial.

\section{APROXIMACIÓN AL DERECHO DE AUTOR Y DERECHOS CONEXOS}

En Ecuador, los derechos de autor y los derechos conexos se encuentran regulados y protegidos por normas nacionales, comunitarias, e internacionales. A nivel nacional, la norma aplicable es el Código Orgánico de la Economía Social de los Conocimientos (COESC) y su reglamento, a nivel comunitario la Decisión 351, la cual goza de aplicabilidad inmediata, efecto directo y primacía, ${ }^{1}$ y a nivel internacional el Convenio de Berna para la Protección de las Obras Literarias y Artísticas, la Convención de Roma y el Tratado de la OMPI sobre Interpretación o Ejecución y Fonogramas (TOIEF).

1. Tribunal de Justicia de la Comunidad Andina, Proceso 225-IP-2015, Interpretación Prejudicial, 23 de junio de 2016. 


\section{Derechos de AUTOR}

El derecho de autor puede definirse como la protección jurídica conferida al creador o autor de una obra artística, científica o literaria, producto de su ingenio, inventiva o intelecto, para el ejercicio de derechos de naturaleza moral y patrimonial respecto de sus obras.

En el Proceso 110-IP-2007, infracción a derechos de autor, publicado en la Gaceta Oficial n. ${ }^{\circ}$ 1588, de 20 de febrero de 2008, el Tribunal de Justicia de la Comunidad Andina ha determinado el objeto de protección de los derechos de autor y su ámbito de protección, de la siguiente manera:

El derecho de autor protege todas las manifestaciones originales, literarias, artísticas y científicas, que sean fruto del ingenio humano, cuando ellas son o puedan ser accesibles a la percepción sensorial y puedan ser objeto de reproducción por cualquier medio apto para tal finalidad. Es un derecho que se ejerce sobre un bien inmaterial soportado en obras de naturaleza artística, literaria o científica y que está regulado y es objeto de protección por los diferentes ordenamientos jurídicos estatales y, también, por los comunitarios, como sucede en el ordenamiento comunitario andino donde este derecho se regula por la Decisión $351[\ldots]$.

El autor goza de derechos morales y patrimoniales. El derecho moral está ligado a la persona del autor por el hecho de haber creado la obra, es decir, que le permite ser reconocido como autor o creador de la obra erga omnes y conservar su titularidad sobre la misma durante toda su vida. Shakespeare, por ejemplo, pese a que una de sus obras más famosas, Romeo y Julieta, ha pasado por un sinnúmero de representaciones, modificaciones, adaptaciones, siempre será el autor de la obra original. Este derecho, además, permite al autor conservar la obra inédita o divulgarla; reivindicar su paternidad; exigir que se mencione o se excluya su nombre o seudónimo cada vez que la obra sea utilizada; oponerse a toda deformación, mutilación, alteración o modificación que atente contra su decoro, honor o reputación; $\mathrm{y}$, acceder al ejemplar único o raro de la obra cuyo soporte se encuentre en posesión o sea de propiedad de un tercero, a fin de ejercitar el derecho de divulgación o cualquier otro que le corresponda. ${ }^{2}$

Por otro lado, los derechos patrimoniales permiten al autor obtener un provecho económico de la obra o creación a través de su publicación, reproducción o divulgación. A diferencia de los derechos morales, los patrimoniales sí son transmisibles a terceros a través de diversas modalidades y son perecederos hasta setenta años des-

2. Ecuador, Código Orgánico de la Economía Social de los Conocimientos, Registro Oficial Suplemento 899, de 9 de diciembre de 2016, art. 118. COESC en lo sucesivo. 
pués de la muerte de su autor, momento en que la obra pasa al dominio público. Por medio de este derecho, el autor puede controlar la explotación económica de la obra, sea que se beneficie de forma directa o a través de terceros autorizados, participando económicamente de esa explotación. ${ }^{3}$ El artículo 120 del COESC, respecto de los derechos patrimoniales, establece que se reconocerán a favor del autor el derecho a la reproducción; comunicación pública; ${ }^{4}$ distribución; importación de copias; traducción, adaptación, arreglo u otra transformación de la obra; y puesta a disposición del público de sus obras.

El ius prohibendi es la potestad principal que conceden los derechos de propiedad intelectual. El derecho de autor atribuye a su titular un derecho de exclusiva para poner en práctica o reproducir su creación y a la vez impedir que otros lo hagan sin su consentimiento. ${ }^{5}$ Sin esta protección, los autores perderían el beneficio económico que les representa su obra, y con ello el incentivo de continuar creando y el campo de las artes, la literatura y en general de la creación desaparecería poco a poco.

Si bien la protección por el derecho de autor es automática, es decir, por el hecho de la creación de la obra, sin requerir de un registro previo ${ }^{6}$ (a diferencia de las marcas o patentes que sí lo requieren), no toda expresión creativa se encuentra dentro del ámbito de protección del derecho de autor. Existen ciertos requisitos fundamentales que deberán cumplirse. El COESC, en su artículo 104 contempla las condiciones para que una obra sea susceptible de protección bajo derecho de autor: "La protección reconocida por el presente Título recae sobre todas las obras literarias, artísticas y científicas, que sean originales y que puedan reproducirse o divulgarse por cualquier forma o

3. Alfredo Vega Jaramillo, Manual de derecho de autor (Bogotá: Dirección Nacional de Derecho de Autor, 2010), 35.

4. Tribunal de Justicia de la Comunidad Andina, Interpretación Prejudicial, Proceso 39-IP-99, 1 de diciembre de 1999: Una forma de comunicación pública es la representación y ejecución pública, que es uno de los procedimientos para hacer comunicar las obras artísticas y literarias a varias personas, a través de medios distintos de la distribución de ejemplares. Sus principales requisitos consisten en la inexistencia de un vehículo material para que se pueda acceder a la obra y en la destinación de la comunicación a una pluralidad de personas calificadas como "público". La noción estricta de representación se refiere a las obras dramáticas, dramático-musicales, coreográficas o pantomímicas, comunicadas a través de la escenificación.

5. Ricardo Mata y Martín, "Repercusiones del sistema normativo de la Unión Europea sobre la configuración de los delitos relativos a la propiedad industrial", en La aplicación privada del derecho de la competencia, ed. por Luis Antonio Velasco San Pedro et al. (Valladolid: Lex Nova, 2011), 881.

6. Tribunal de Justicia de la Comunidad Andina, Proceso 044-IP-2013, 16 de julio de 2013: "El registro en el ordenamiento comunitario andino no funge como elemento constitutivo de derechos y el que se realice o no, carece de relevancia en cuanto al goce o al ejercicio de los derechos reconocidos por la ley al autor de la obra". 
medio conocido o por conocerse". Podemos entonces identificar cuatro principales requisitos que deberán cumplirse para que una obra creativa pueda ser protegida:

i. Existencia de una obra. La primera referencia que hace el artículo 104 del COESC es que la protección recae sobre "todas las obras literarias, artísticas y cientificas, que sean originales" (énfasis añadido), es decir que, si no hay una obra como tal, nada tiene el derecho de autor que proteger. Se entiende por obra: "Cualquier producto intelectual en ciencias, letras o artes, y con particularidad el que es de alguna importancia". ${ }^{7}$ Por tanto, una obra es el resultado de un trabajo, de un proceso creativo propio del autor que deberá materializarse en una forma expresiva para poder ser protegida. El soporte material no necesariamente se refiere a una $\cos a$ sino a que la idea se encuentre plasmada, descrita, desarrollada, ilustrada o incorporada en un material distinguible y perceptible por los seres humanos. ${ }^{8}$ La idea, al no ser observable ni perceptible, no puede protegerse en sí misma, ${ }^{9}$ pero sí puede protegerse el fruto de esa idea, materializado en una forma de expresión.

ii. Que sea literaria, artística o científica. Son muchas las obras que se nos vienen a la cabeza al pensar en estos tres tipos. El Convenio de Berna en su artículo 2 esclarece lo que podemos entender por obras literarias y artísticas al prever una lista ejemplificativa de obras de este tipo, pero pueden existir muchas más. El derecho de autor protegerá la forma o medio de expresión de la idea, independientemente de cuál sea o de si se conoce o no todavía. Por lo tanto, toda obra expresada, ya sea de forma escrita, oral, lingüística, plástica, audiovisual, musical, sonora, gestual, corporal, gráfica, etc., entraría dentro del ámbito protegible, siempre y cuando reúna los demás requisitos.

iii. Originalidad. Este bien puede considerarse como el requisito determinante para que una obra pueda protegerse por el derecho de autor o esté fuera de su ámbito de protección. Además del artículo 104 del COESC, la Decisión 351 señala que obra será "Toda creación intelectual original", por lo que sin el factor de originalidad no habría lugar a una protección de ningún tipo.

La originalidad está estrechamente relacionada con la personalidad del autor. Esto se refiere a que no debe haber duda alguna respecto a que la obra creada por el autor provenga de su origen, de lo más íntimo de su personalidad y en donde se manifieste su desarrollo intelectual. ${ }^{10}$ En la doctrina colombiana, se

7. Real Academia Española (RAE), Diccionario de la lengua española, 23. ${ }^{a}$ ed., 〈http://www.rae.es/>.

8. Juan Pablo Canaval Palacios, Manual de propiedad intelectual (Bogotá: Universidad del Rosario, 2008), 34.

9. COESC, art. 102.3.

10. Canaval Palacios, Manual de propiedad intelectual, 34. 
requiere que la obra sea producto del esfuerzo intelectual del autor. ${ }^{11}$ Esta forma de originalidad se conoce como subjetiva e implica que la obra sea algo único, inédito, capaz de reflejar la personalidad del autor y de distinguirse de otras del mismo género. Por otro lado, como otro parámetro para determinar la originalidad de una obra, tenemos lo que se conoce como originalidad objetiva. Esta, al contrario de la subjetiva, está basada en la novedad en el sentido de que la obra para ser original no debe ser copia de otra obra preexistente. ${ }^{12}$

iv. Reproducción o divulgación de la obra. Este requisito va de la mano con el primero respecto de la existencia de una obra con un soporte material, o mejor dicho apreciable por los sentidos. Cumplir con este requisito da a la obra la facultad de ser reproducida y divulgada. Si la obra no ha sido plasmada o exteriorizada significa que se ha quedado en la idea.

El criterio del Tribunal Supremo español es muy esclarecedor respecto del nacimiento de la protección de las obras creativas; "en cualquier caso es necesario acreditar la existencia de la obra, entendida no como un conjunto de ideas o de información que el autor pudiera tener en su mente, sino en la medida en que consta exteriorizada por cualquier medio o soporte, tangible o intangible". ${ }^{13}$ Bastaría con que la obra haya sido transmitida a un tercero (público) para que deje de ser idea y sea demostrable su existencia, sin necesidad de que se haya realizado una primera divulgación o reproducción.

\section{DERECHOS CONEXOS: PROTECCIÓN}

\section{A ARTISTAS, INTÉRPRETES O EJECUTANTES}

Se debe distinguir entre la obra que se representa y la puesta en escena de la misma. ${ }^{14}$ La primera es fruto de la creatividad del autor y objeto de protección del derecho de autor y la segunda es una actividad protegida por los llamados derechos conexos, salvo aquellos elementos en escena que por su grado de originalidad pudieran considerarse obras susceptibles de protección por el derecho de autor, según analizaremos más adelante.

11. Ernesto Rengifo García y Universidad Externado de Colombia, Propiedad intelectual: el moderno derecho de autor (Bogotá: Universidad Externado de Colombia, 1996), 78.

12. José Luis Caballero Leal, Derecho de autor para autores (México D. F.: Cerlalc / Libraria / Fondo de Cultura Económica, 2004), 3.

13. España, Tribunal Supremo, "Sentencia", n. " 778/2012 (ROJ: STS 8998/2012), 27 de diciembre de 2012.

14. Adriana Moscoso del Prado y Jaume Colomer Vallicrosa, edit., Guía legal y financiera de las artes escénicas en España (Madrid: Instituto de Derecho de Autor, 2012), 96. 
Los derechos conexos son independientes pero a la vez compatibles con el derecho de autor, y reconocen a "ciertos sujetos que contribuyen de diversa forma a que una obra se difunda y llegue a ser conocida por el público, o bien que han desarrollado una actividad creativa sobre una obra preexistente". ${ }^{15}$ Dentro de esta categoría de derechos se incluyen los que corresponden a artistas, intérpretes o ejecutantes, a productores de fonogramas y a organismos de radiodifusión.

Los derechos conexos denotan una afinidad con los derechos de autor por su estrecha relación con la difusión y explotación de la obra. Lo que buscan es asegurar una protección autónoma y más idónea de la que podría recibirse mediante cesión o licencia de derechos de autor. Además, la protección atiende a la propia estructura y naturaleza del derecho reconocido a su titular, similar al derecho de autor. Asimismo, los derechos conexos aseguran un derecho de exclusiva sobre un objeto peculiar, también inmaterial o incorporal, y comprenden, en los mismos términos que el derecho de autor respecto a la obra, todas las facultades correspondientes a cualquier clase de utilización o explotación posible durante su vigencia. ${ }^{16}$ Por la naturaleza del presente ensayo, nos enfocaremos en analizar únicamente los derechos conexos correspondientes a artistas, intérpretes o ejecutantes, en adelante solo artistas.

La protección a los artistas recae sobre su actuación entendida como la versión concreta y propia que hayan efectuado de la ejecución o de la interpretación de una obra. ${ }^{17}$ Las principales justificaciones para que estas no sean consideradas obras consisten en que están exentas de creatividad personal y cumplen una función de mediación entre autor y público, y no de creación. ${ }^{18}$ Los artistas no adquieren la condición de autores porque su actuación o interpretación requiere la existencia previa de una obra, con lo cual la protección que reciben se centra en esa actividad que desarrollan a partir de una creación existente, ${ }^{19}$ lo que le resta originalidad. Es decir, no son autores en sentido estricto, pero sí desarrollan una actividad creativa al interpretar una pieza teatral o musical. ${ }^{20}$

15. Carlos Rogel Vide y Eduardo Serrano Gómez, Manual de derecho de autor (Madrid: Reus, 2008), 145.

16. Rodrigo Bercovitz Rodríguez-Cano, Manual de propiedad intelectual, $4 .{ }^{\mathrm{a}}$ ed. (Valencia: Tirant lo Blanch, 2009), 28.

17. Ibíd., 212 .

18. Antonio Delgado Porras, "Propiedad intelectual, derecho de autor y derechos conexos (afines) al de autor: nociones generales", en Derechos de autor y derechos afines al de autor, ed. por Antonio Delgado Porras, vol. 1 (Madrid: Instituto de Derecho de Autor, 2007), 290.

19. La obra previamente existente puede ser ajena o propia al artista, en cuyo caso tendría simultáneamente la condición de autor y artista.

20. Rogel Vide y Serrano Gómez, Manual de derecho de autor, 146. 
El elemento objetivo sobre el cual se ejerce el correspondiente derecho de los artistas está constituido por sus interpretaciones o ejecuciones. ${ }^{21} \mathrm{~A}$ diferencia del resto (productores de fonogramas y organismos de radiodifusión), se debate si a los artistas, además del derecho de exclusiva que es netamente patrimonial, les corresponde un derecho moral sobre sus interpretaciones o ejecuciones. Si bien en su generalidad sus interpretaciones no pueden considerarse obras bajo la definición de derecho de autor, pues carecen de originalidad, se debe considerar que, como bien indica Rodrigo Bercovitz:

Las actuaciones de los artistas constituyen creaciones personales, en las que entra en juego la imagen de aquellos (su voz, su físico, sus gestos) y que frecuentemente alcanzan un nivel elevado de originalidad (altura creativa). Sin embargo, no se les considera autores (de una obra derivada de la que interpretan o ejecutan) ni se equipara el contenido de su derecho con el de aquellos. ${ }^{22}$

Esto nos lleva a reflexionar acerca del nivel de protección que adquieren los actores y demás involucrados en una obra escénica. Es cierto que el derecho de autor corresponde a los creadores de obras y los derechos conexos a los productores (con una connotación de interés empresarial o de negocio); por consiguiente, ¿qué pasa con los artistas que sin llegar a ser considerados autores de obras, ostentan un alto grado de creatividad personal en su actuación y no encajan en un tipo de derecho u otro?

$\mathrm{Al}$ igual que los autores, los artistas se ven amenazados por la existencia de medios tecnológicos que permiten que sus actuaciones e interpretaciones sean fijadas y, por lo tanto, susceptibles de explotación. Pueden ser reproducidas, distribuidas o comunicadas a un público fuera de las salas. En consecuencia, es preciso que los artistas reciban también una protección suficiente, acorde con su creación.

\section{SITUACIÓN DE LAS ARTES ESCÉNICAS EN ECUADOR}

El COESC, en su artículo 104, contiene una lista de obras cuya protección podría denotarse obvia. Esta lista es ejemplificativa y no taxativa, y encontramos cuatro numerales que son de nuestro principal interés y serán objeto de análisis a lo largo del presente documento:

21. Delgado Porras, "Propiedad intelectual, derecho de autor y derechos conexos (afines) al de autor: nociones generales", 290.

22. Bercovitz Rodríguez-Cano, Manual de propiedad intelectual, 28. 
1. Las obras expresadas en libros, folletos, impresos, epistolarios, artículos, novelas, cuentos, poemas, crónicas, críticas, ensayos, misivas, guiones para teatro, cinematografía, televisión, conferencias, discursos, lecciones, sermones, alegatos en derecho, memorias y otras obras de similar naturaleza, expresadas en cualquier forma; [...]

3. Obras dramáticas y dramático-musicales, las coreografías, las pantomimas y, en general las obras teatrales; [...]

6. Las esculturas y las obras de pintura, dibujo, grabado, litografía y las historietas gráficas, tebeos, cómics, así como sus ensayos o bocetos y las demás obras plásticas [...]

7. Proyectos, planos, maquetas y diseños de obras arquitectónicas y de ingeniería;

Asimismo, el artículo 4 de la Decisión 351 de la CAN, contempla en el mismo sentido lo siguiente:

a) Las obras expresadas por escrito, es decir, los libros, folletos y cualquier tipo de obra expresada mediante letras, signos o marcas convencionales; [...]

d) Las obras dramáticas y dramático-musicales;

e) Las obras coreográficas y las pantomimas; [...]

g) Las obras de bellas artes, incluidos los dibujos, pinturas, esculturas, grabados y litografías $[\ldots]$

h) Las obras de arquitectura;

En el mismo sentido, el Convenio de Berna se refiere a la protección de las artes escénicas en su artículo 2.1., y además concede ciertos derechos exclusivos a los autores de obras dramáticas y musicales:

1) Los autores de obras dramáticas, dramático-musicales y musicales gozarán del derecho exclusivo de autorizar:

(i) la representación y la ejecución pública de sus obras, comprendidas la representación y la ejecución pública por todos los medios o procedimientos;

(ii) la transmisión pública, por cualquier medio, de la representación y de la ejecución de sus obras.

2) Los mismos derechos se conceden a los autores de obras dramáticas o dramático-musicales durante todo el plazo de protección de sus derechos sobre la obra original, en lo que se refiere a la traducción de sus obras.

De la lectura de estos artículos podemos dilucidar, en una primera instancia, que las artes escénicas están protegidas por el derecho de autor. Sin embargo, la norma no hace ninguna otra referencia expresa a la forma en que todos estos elementos pueden ser protegidos atendiendo a su naturaleza particular, ni en qué medida pueden serlo.

Surgen entonces las siguientes interrogantes: ¿quiénes son titulares de los derechos de autor?; ¿qué régimen de protección es aplicable: derechos de autor o derechos conexos?; ¿cuáles obras son protegidas bajo el derecho de autor o derechos conexos y 
en qué medida? Para dar respuesta a estas interrogantes debemos partir de dos ideas fundamentales. Existe, por un lado, la obra escénica como tal, que nace a partir de la conjunción de varios autores y elementos creativos, y dependiendo de su puesta en escena podría ser protegida o no. Por otro lado, existen elementos creativos que dependiendo de su naturaleza, podrían a su vez considerarse una obra protegible por los derechos de autor en sí mismos, o por derechos conexos. A continuación analizaremos las respuestas que nos ofrece la legislación.

\section{SObRe LA TITULARIDAD DE LOS DERECHOS}

\section{DE AUTOR EN LAS ARTES ESCÉNICAS}

El derecho de autor, el autor intelectual creador de la obra será el titular originario sobre la misma y por ende el titular de los derechos morales y patrimoniales. Esta titularidad puede pertenecer a un solo autor o a una pluralidad, en cuyo caso podrían denominarse coautores. En el primer caso se trata de una obra individual y en el segundo dependerá de la forma en que los autores involucrados participen para clasificarla como obra colectiva ${ }^{23} \mathrm{u}$ obra en colaboración. Cabe aclarar que esta forma de titularidad se refiere únicamente a autores y no a artistas bajo régimen de derechos conexos.

\section{La obra individual}

Cuando solo un autor participa en la creación de una obra, se trata de una obra individual. En el caso de las artes escénicas, lo más común es que existan varios participantes o al menos un director y un actor. Sin embargo, pueden existir algunas obras en que interviene un solo autor, como por ejemplo los monólogos o stand up comedy que bien podrían ser creados, coordinados e interpretados por el mismo autor. En este último caso nos encontramos frente al ejemplo perfecto de un titular tanto de derechos de autor como de derechos conexos al ser a la vez autor e intérprete.

\section{Pluralidad de autores en las artes escénicas}

Toda obra escénica se caracteriza por la complejidad de sus elementos pertenecientes a diversos campos de la actividad creativa (música, letra, narración, luz, decorados,

23. COESC, art. 113. 
vestuarios, figuración, danza, etc.), razón para sea frecuente la conjunción de varias personas en la autoría. ${ }^{24} \mathrm{El} \mathrm{COESC}$ contempla dos formas de obras con pluralidad de actores: las obras en colaboración y las obras colectivas.

a) Obras en colaboración. Este tipo de obras, implica una labor compartida, es decir, que varios autores participan realizando aportaciones de tipo individual, con miras a la consecución de un fin común. ${ }^{25}$ Cada participante de la pieza escénica participa con su propia creación para dar lugar a la obra en concreto. Se trata de un trabajo compartido en el cual los autores aportan su obra creativa para que el resultado común, que en este caso sería la obra escénica, ocurra. El artículo 112 del COESC, hace énfasis en que se apunta a un resultado unitario que "deviene de la colaboración de varios autores", por lo que puede entenderse que lo que motiva a la creación de cada una de las obras individuales es dar lugar a la obra común. Este tipo de obras tienen la característica especial de que, según el mismo artículo 112 del COESC, para ser divulgadas o modificadas se requerirá el consentimiento de todos los autores. Pero eso sí, una vez divulgada la obra, ningún coautor podrá rehusar la explotación de la misma en la forma en que se divulgó.

Las obras en colaboración pueden ser divisibles e indivisibles. Cuando son divisibles, las aportaciones creativas de cada autor son identificables y pueden individualizarse, separarse del resto y ser protegibles en sí mismas. Este podría decirse que es el caso más común en obras de teatro, ópera o ballet en que pueden intervenir el autor de la obra dramática (el texto), el director de escena, los actores, coreógrafos, los escenógrafos, los diseñadores de luces, entre otros; e incluso el público sin el cual la obra no existiría. En este caso pueden identificarse, dividirse, e incluso explotarse de forma separada, por ejemplo el guion o libreto, la composición musical y la interpretación teatral o de danza. Cada autor es titular de los derechos sobre la parte de la obra aportada y, salvo pacto en contrario, cada colaborador podrá explotar separadamente su aportación, a menos que cause perjuicio a la explotación común de la obra.

Cuando la obra en colaboración es indivisible, significa, por el contrario, que el resultado de los aportes de los diferentes creadores no permite identificar de modo alguno las contribuciones individualmente realizadas, como consecuencia de la fusión o integración que tienen entre sí. Es decir que no son separables unas de otras. En este caso, salvo pacto en contrario, los derechos pertenecen en común y proindiviso a todos los coautores. No se requiere, salvo pacto en contrario, el consentimiento de los demás autores si uno de ellos quiere explotar la obra resultante, siempre que no perjudique a la explotación normal de la obra y sin perjuicio de repartir a prorrata los

24. Bercovitz Rodríguez-Cano, Manual de propiedad intelectual, 62.

25. Caballero Leal, Derecho de autor para autores, 6. 
beneficios económicos obtenidos de la explotación previa deducción de los gastos efectuados. ${ }^{26}$

b) Obras colectivas. Este tipo de obras, por el contrario, son creadas bajo la iniciativa y dirección de una persona natural o jurídica que las divulga bajo su propio nombre. Las aportaciones de los autores que participan se funden entre sí de forma que es imposible atribuir a cada uno de ellos un derecho distinto, individualizable o separable de la obra. ${ }^{27}$ Puede ser que participe un número tan elevado de autores que sea imposible de identificar el aporte de cada uno. De esta manera, se requiere en primer lugar una persona física o jurídica que tenga iniciativa o decida dar nacimiento a una obra determinada, que posteriormente coordine y dirija a los demás autores en el proceso de creación de la obra y que una vez entregadas cada una de las aportaciones, edite y divulgue la obra bajo su nombre, como si fuera de su autoría. En este caso, el titular de los derechos sería únicamente esta persona física o jurídica.

Cabe señalar una particularidad que presenta nuestra normativa nacional. Pese a su principal característica de ser indivisible, el COESC en su artículo 113 ofrece la posibilidad de separar los aportes de cada autor y explotarlos individualmente, siempre que se haga de buena fe y no se perjudique injustificadamente la explotación normal de la obra colectiva.

Los ejemplos por excelencia de este tipo de obras son los diccionarios, enciclopedias, programas de computación o bases de datos electrónicas. Sin embargo, puede darse en el caso de las artes escénicas que todo el trabajo de los autores involucrados se realice por iniciativa y bajo la dirección y coordinación del director de escena. Por lo general, el director es quien ensambla el contenido de las diferentes colaboraciones bajo un sentido común, en un resultado unitario que es la obra escénica ${ }^{28}$. En la ópera, por ejemplo, el compositor musical puede cumplir con los presupuestos para que la obra sea colectiva y no en colaboración. Se dice que Verdi actuaba de esta manera, era autor de la composición musical pero a la vez dirigía directamente el trabajo de los autores de los libretos.

\section{Aplicación del RÉGIMEN de derechos coneXos}

En Ecuador, los derechos conexos están regulados por la Decisión 351, la Convención de Roma, el Tratado de la OMPI sobre Interpretación o Ejecución y Fonogramas (TOIEF) y el COESC.

26. COESC, art. 112.

27. Caballero Leal, Derecho de autor para autores, 7.

28. Cristina Soler Benito, Artes escénicas y derechos de autor (Madrid: Reus, 2016), 49. 
Según la Decisión 351 de la Comunidad Andina (y también el COESC), se puede definir a los artistas, intérpretes o ejecutantes como: "Persona que representa, canta, lee, recita, interpreta o ejecuta en cualquier forma una obra". ${ }^{29}$ Por su parte, la Convención de Roma ejemplifica más ampliamente y los define como: "todo actor, cantante, músico, bailarín u otra persona que represente un papel, cante, recite, declame, interprete o ejecute en cualquier forma una obra literaria o artística". ${ }^{30}$ Más allá de cualquier definición, lo que los determina, es que su actividad recae sobre obras.

Nuestra legislación, reconoce a los artistas dos tipos de derechos: derechos morales y derechos patrimoniales. Los derechos morales conceden al artista el derecho de ser identificados como tales y el derecho de oponerse a toda distorsión, mutilación u otra modificación de su interpretación o ejecución, que cause un daño a su honra o reputación. ${ }^{31}$. Además, tendrán derecho a conservar la obra inédita o a divulgarla y a reivindicar la paternidad de la obra en cualquier momento. ${ }^{32}$

Los derechos morales de los artistas, a diferencia de los autores, sí tienen un plazo de duración limitado por la vida del artista, luego de lo cual pasan a sus causahabientes por un plazo igual al de los derechos patrimoniales, es decir, setenta años contados a partir del primero de enero del año siguiente a aquel en que tuvo lugar la interpretación o ejecución, o de su fijación, según el caso. ${ }^{33}$

Los derechos patrimoniales conceden al artista la potestad exclusiva para autorizar o prohibir:

1. Respecto de sus interpretaciones no fijadas: su radiodifusión y comunicación pública, así como su fijación en un medio que permita su comunicación o la obtención de copias de toda o parte de ella.

2. Respecto de sus interpretaciones fijadas:

a) La reproducción directa o indirecta por cualquier medio o procedimiento.

b) La distribución, que incluye el alquiler comercial al público del original y de las copias del mismo.

29. Comunidad Andina, Decisión 351. Régimen Común sobre Derecho de Autor y Derechos Conexos, 17 de diciembre de 1993, 〈http://www.comunidadandina.org/StaticFiles/DocOf/DEC351.pdf), art. 3. Ver también COESC, art. 223.

30. Naciones Unidas, Convención de Roma sobre la protección de los artistas intérpretes o ejecutantes, los productores de fonogramas y los organismos de radiodifusión, 26 de octubre de 1961, 〈https://wipolex. wipo.int/es/treaties/textdetails/12656;, art. 3.a.

31. COESC, art. 223.

32. Comunidad Andina, Decisión 351. Régimen Común sobre Derecho de Autor y Derechos Conexos, art. 11.

33. COESC, arts. 223 y 227. 
c) La puesta a disposición al público, ya sea por hilo o por medios inalámbricos, de tal manera que los miembros del público puedan tener acceso a ellas desde el lugar y en el momento en que cada uno de ellos elija. ${ }^{34}$

Además de lo citado anteriormente, la Decisión 351 incluye como derecho exclusivo del artista a autorizar o prohibir: la importación al territorio de cualquier país miembro de copias hechas sin autorización del titular del derecho y la traducción, adaptación, arreglo u otra transformación de la obra. ${ }^{35}$

Por su naturaleza, las actuaciones de los artistas dentro de una obra escénica no se encuentran fijadas en ningún medio (salvo excepciones ${ }^{36}$ ), por lo que se les reconoce el derecho exclusivo de comunicación pública, entendida según el artículo 15 de la Decisión 351 como:

todo acto por el cual una pluralidad de personas, reunidas o no en un mismo lugar, pueda tener acceso a la obra sin previa distribución de ejemplares a cada una de ellas, y en especial las siguientes: a) Las representaciones escénicas, recitales, disertaciones y ejecuciones públicas de las obras dramáticas, dramático-musicales, literarias y musicales, mediante cualquier medio o procedimiento. ${ }^{37}$

Por otro lado, en el caso de que las actuaciones de los artistas sean fijadas en fonogramas o en grabaciones audiovisuales con fines comerciales, el artista tendrá derecho a recibir una remuneración equitativa. Dicha remuneración corresponde al uso directo o indirecto para la radiodifusión, y cualquier otra forma de comunicación pública, de las interpretaciones y ejecuciones fijadas en fonogramas con fines comerciales, o en fijaciones audiovisuales. Adicionalmente, se reconoce la remuneración equitativa a favor de los artistas por la puesta a disposición y el arrendamiento de sus interpretaciones y ejecuciones fijadas en fijaciones audiovisuales. ${ }^{38}$

En consecuencia, la protección a los artistas participantes en una obra escénica radica en primer lugar en el derecho exclusivo a realizar, autorizar o prohibir la comunicación pública de sus actuaciones. En segundo lugar, en caso de que estas sean fijadas en fonogramas con fines comerciales o en grabaciones audiovisuales, el artista deberá recibir una remuneración equitativa por cada acto de comunicación, efectiva a través de entidades de gestión colectiva.

34. COESC, art. 224.

35. Comunidad Andina, Decisión 351. Régimen Común sobre Derecho de Autor y Derechos Conexos, art. 13.

36. Cuando constituyan por sí mismas una ejecución radiodifundida, o la comunicación se realice a partir de una fijación previamente autorizada.

37. Comunidad Andina, Decisión 351. Régimen Común sobre Derecho de Autor y Derechos Conexos, art. 15.

38. COESC, art. 225 . 


\section{Protección de los elementos CReativos en UNA ObRa ESCÉNICA}

Para que la pieza escénica ocurra convergen, en la mayoría de los casos, principalmente tres partes: a) la obra literaria; b) la obra puesta en escena c) la escenografía y decorados en escena (que podría llegar a incluir obras arquitectónicas). Como hemos mencionado antes, tanto el COESC (artículo 104), como la Decisión 351 (artículo 4) y el Convenio de Berna (artículo 2.1) citados anteriormente, consideran obras susceptibles de protección a cada una de estas partes y confieren el mismo nivel de protección. Sin embargo, la norma no menciona ni diferencia los elementos individuales dentro de cada una de ellas, ni su tratamiento o nivel de protección, lo cual pasaremos a analizar a continuación.

\section{La obra literaria}

Es decir, el texto teatral o mejor conocido como el guion o la dramaturgia de la pieza escénica, en la mayoría de los casos constituye la base o el origen de lo que será, en lo posterior, llevado a escena. Los textos teatrales son considerados obras en el mismo renglón y consideración que las demás obras literarias convencionales, las novelas, la poesía, la ensayística; ${ }^{39}$ y por lo tanto, merecen la misma protección bajo el derecho de autor que cualquier otra obra de tipo literario que cumpla con los requisitos de protección mencionados anteriormente.

\section{La obra puesta en escena}

Podemos dilucidar respecto de las artes escénicas que, bajo el COESC, la Decisión 351 y el Convenio de Berna, se considera expresamente a las obras dramáticas o dramático-musicales, las obras coreográficas y las pantomimas como obras literarias y artísticas susceptibles de protección por el derecho de autor. Las tres normas son precisas al distinguir entre estos tipos de obras, pues cada una presenta sus particularidades y formas de expresión propias (a través de la palabra, el canto, la gesticulación y la danza). En las coreografías y pantomimas, se persigue también una representación escénica que tiene como medio de expresión fundamental al lenguaje del cuerpo, movimientos, gestos, señas, muecas, ademanes. En la pantomima dominan los gestos a través de los cuales se producen las escenas, mientras que en las obras coreográficas se representa la escena a través del baile de piezas musicales. En ambos casos se

39. Soler Benito, Artes escénicas y derechos de autor, 12. 
protege la sucesión de gestos y movimientos en función de una estructura armónica preordenada. ${ }^{40}$

Mucho dependerá la forma en que la obra es llevada a escena para que esta como tal, y luego cada uno de sus elementos por separado, cumplan con los requisitos para ser considerados dentro del ámbito de protección de los derechos de autor, o de los derechos conexos.

Los requisitos de protección que se refieren a la existencia de una obra como tal, que pueda reproducirse o divulgarse en cualquier forma o medio, son fácilmente entendibles en el caso de la literatura y la fotografía en que la idea del autor es plasmada en las páginas de un libro que contiene la obra literaria, o en el papel fotográfico que contiene la imagen captada por el fotógrafo en su cámara. Sin embargo, una obra escénica no se limita a un solo tipo de soporte material sino que se trata de un suceso, de un acontecimiento efímero en el que convergen una serie de elementos apreciables y perceptibles por los sentidos.

Ahora bien, de las características propias de la pieza escénica dependerán también los tipos de creaciones y su forma de expresión. Por ejemplo, existe por un lado la interpretación teatral de los actores empleando su cuerpo y su voz para caracterizar un personaje y expresar lo que este tiene que decir al público, por otro puede existir interpretación musical, danza o también comunicación únicamente gestual como en el caso de la pantomima. Todas estas formas de expresión son efímeras y receptadas por un tercero mientras suceden y por lo tanto existen y pueden considerarse obras en sí mismas pese a que no estén contenidas en un soporte material como tal. Además, según se mencionó anteriormente, el COESC establece en el artículo 101 que los derechos reconocidos y concedidos por el derecho de autor son independientes de la propiedad del objeto material en el cual está incorporada la obra o prestación y el 102 reconoce que los derechos de autor nacen y se protegen por el solo hecho de la creación de la obra. En consecuencia, enfocándonos a las artes escénicas, la ausencia de un objeto material que contenga la obra teatral o de una divulgación o reproducción previa, no disminuye su capacidad de ser protegida, siempre y cuando se demuestre su existencia por el hecho de ser apreciable por los sentidos y sea una creación original.

La originalidad por su parte, debe buscarse en la puesta en escena propiamente dicha, en los elementos que la componen: en el ritmo, el estilo interpretativo, la caracterización, el contexto escenográfico, los intervalos y las transiciones, los silencios, etc. ${ }^{41}$ Una obra escénica, principalmente el teatro o la ópera, puede montarse con

40. Bercovitz Rodríguez-Cano, Manual de propiedad intelectual, 62.

41. Soler Benito, Artes escénicas y derechos de autor, 255. 
un estricto apego a un guion teatral que describa minuciosamente la escenografía, el grado de iluminación y no solo las palabras sino también los movimientos de los actores, sin que la creatividad del director, actores y demás participantes del hecho teatral pueda exteriorizarse. En este caso será el autor, entendido como el dramaturgo, el principal protegido por el derecho de autor por ser quien ha materializado su idea en el guion teatral. En una representación escénica de este tipo, no solo que será muy difícil separar cada elemento creativo convirtiéndose en una obra colectiva y no en colaboración, sino que los demás participantes del hecho teatral, como es el caso de los actores, podrían ser considerados intérpretes o ejecutantes, mas no autores, y serán titulares únicamente de derechos conexos y no de derechos de autor.

Por lo tanto, mientras mayor libertad tengan los directores y participantes del hecho escénico, y puedan estos materializar su personalidad o dejar su huella creativa en la escena, mayor será la originalidad de la obra y la posibilidad de ser protegida por los derechos de autor. Una vez que la obra en conjunto es protegible, habrá que analizar si cada uno de los elementos creativos que la conforman podrían cumplir también con los requisitos de protección en sí mismos para considerarse como obras protegibles individualmente. A continuación, mencionaremos brevemente los principales participantes creativos que componen la pieza escénica:

i. Dramaturgo. En las artes escénicas, se identifica al dramaturgo como el autor de la obra original, es decir la persona que escribió el texto teatral. Este puede actuar como director, actor, escenógrafo, etc. Así, se define al autor dramático como "persona que escribe una obra teatral. Con el actor y director, es uno de los pilares básicos en el desarrollo y evolución de las artes dramáticas". ${ }^{42}$ En primera instancia, no hay lugar a dudas de que el dramaturgo será considerado como autor y le corresponderá el ejercicio de sus derechos de autor como sucede con cualquier otro autor de una obra literaria.

ii. Director (de escena). Sin duda desempeña un papel principal dentro de las artes escénicas. Es la persona que tiene a su cargo la dirección y la puesta en escena de la obra dramática original. ${ }^{43} \mathrm{El}$ caso de director de escena es uno de los más controvertidos, pues comúnmente es considerado como un mero ejecutor de la obra dramática creada por el dramaturgo, sin llegar a ser considerado como un autor en sí mismo, pese al alto nivel creativo que requiere la puesta en escena. Bajo este contexto, sería titular únicamente de derechos conexos como ejecutante de la obra original, mas no de derechos de autor. Sin embargo, el trabajo realizado por el director de escena merece analizarse a mayor profundidad. El

42. Manuel Gómez García, Diccionario Akal de teatro (Madrid: Akal, 1998), 70.

43. Ibíd., 259. 
director de escena es el llamado a montar la pieza escénica que, si bien está basada en la obra dramática original, la forma en que es llevada a escena dependerá de la creatividad del director de escena, y con ello de la forma en que este impregne su personalidad hasta alcanzar la originalidad necesaria para que su trabajo pueda ser considerado como una obra (bajo el concepto del derecho de autor). Por las variantes que podría tener la labor de un director de escena, valdría la pena dejar abierta la posibilidad, en nuestra legislación, de incluir al director de escena en el concepto de autor, en lugar de encasillarlo como ejecutante, acreedor únicamente de derechos conexos.

iii. Actores. Son los encargados de la representación, de la interpretación de personajes, es decir, de dar vida a las escenas. Para recrear las escenas, los actores deberán trabajar de la mano con el resto del equipo, bajo las instrucciones del director de escena, que bien puede ser actor a la vez, dependiendo del caso. Los actores, al igual que los directores de escena, pueden limitarse a seguir las instrucciones del director de escena, o realizar un trabajo creativo de alto nivel al momento de construir o interpretar un personaje. Los actores son expresamente catalogados como artistas o intérpretes, acreedores de derechos conexos y no de autor. Sin embargo, como en el caso del director de escena, si el trabajo del actor alcanza los niveles creativos y de originalidad exigidos por el derecho de autor (como en el común caso de los monólogos o stand up comedies antes mencionados), deberá ser considerado autor y recibir la protección correspondiente bajo el derecho de autor.

iv. Diseñador de vestuario. Es el encargado de diseñar el conjunto de trajes necesarios en la representación escénica. De igual manera, su colaboración en la obra escénica puede ser considerada una creación original si el diseñador de vestuario ha podido efectuar selecciones arbitrarias personales que le permiten impregnar en su creación su huella personal. ${ }^{44}$

v. Músicos. En este caso deberá considerarse el régimen aplicable a los músicos en general. Será considerado autor si el músico es el creador de la composición musical. Por el contrario, si simplemente interpreta una composición musical previamente existente, será considerado intérprete, acreedor de derechos conexos.

44. Soler Benito, Artes escénicas y derechos de autor, 121. 


\section{La escenografía}

Hemos visto que el COESC y la Decisión 351 y el Convenio de Berna protegen en general las esculturas y las obras de pintura, dibujo, grabado, litografía y las historietas gráficas, tebeos, cómics, así como sus ensayos o bocetos y las demás obras plásticas. Incluso protegen los proyectos, planos, maquetas y diseños de obras arquitectónicas y de ingeniería. En el caso del Convenio de Berna, utiliza este tipo de obras para ejemplificar lo que debe entenderse por obras literarias y artísticas. Por consiguiente, en lo que se refiere también a la escenografía, existe la discusión de si puede ser protegida por derechos de autor si consagra los requisitos de originalidad y exteriorización en soporte material.

En una pieza escénica, la escenografía es fundamental para situar, poner en contexto y ambientar. Las obras dramáticas y dramático-musicales se caracterizan frente a las literarias y a las musicales, respectivamente, precisamente por su escenificación. ${ }^{45} \mathrm{En}$ todo tipo de arte escénica, sea una obra teatral, un concierto o un circo, la escenografía juega un papel preponderante. Jaques Polieri define escenografia como el "conjunto de elementos pictóricos, plásticos, técnicos y teóricos que permiten la creación de una imagen, de una construcción bio tridimensional, o la puesta en el espacio de una acción notablemente espectacular" ${ }^{46}$ La escenografía en una representación escénica incluye todos aquellos elementos que conforman el espacio de una puesta en escena, sean estos dibujos, pinturas, diseños, esculturas, bocetos, maquetas y demás objetos empleados en la puesta en escena. Como señala Germán Bercovitz, "cada uno de los elementos pictóricos, escultóricos o arquitectónicos tiene carácter creativo. Pero el conjunto puede tener también carácter creativo". ${ }^{47}$ Es decir, que cada componente de la escenografía resulta de un proceso creativo, y de igual manera la escenografía como un todo.

Independientemente de si la idea de la escenografía se encuentra descrita en la obra literaria o por el director de escena, será el escenógrafo quien realice todo el proceso creativo de la escenografía, desde la elaboración de los bocetos, planos o diseños, hasta su construcción y montaje. La ejecución personal, la elección de las vías y de los medios corresponde al escenógrafo. Este proceso de alto nivel creativo podría ser suficiente para considerar a la escenografía como una obra original, susceptible de protección bajo derecho de autor. Como señala Rebello, "el decorado, la dirección escénica y los figurines en una obra teatral, cuando sean originales, se consideran propiedad artística de quien

45. Bercovitz Rodríguez-Cano, Manual de propiedad intelectual, 61.

46. Jaques Polieri, Escénographie (París: Jean Michel Place, 1990), citado por Ruth Castellote, "Reconocimiento y protección de los derechos de autor en las escenografías", Revista Icade, n. 78 (2009): 148.

47. Germán Bercovitz, Obra plástica y derechos patrimoniales de su autor (Madrid: Tecnos, 1997), 47-9. 
los haya concebido y realizado". ${ }^{48}$ Sin embargo, nos enfrentamos ante un vacío legal a la hora de protegerla, toda vez que nuestra legislación califica como obras, sin lugar a dudas, a los dibujos, ensayos, bocetos y obras plásticas de forma individual, dejando de lado la escenografía como un conjunto de todas las anteriores.

A diferencia de nuestra legislación, el derecho portugués sí reconoce la escenografía como obra original. En su Código del Derecho de Autor y Derechos Conexos, artículo 2.1(c), incluye en la lista de las obras originales a las obras dramáticas y dramático-musicales y su escenificación, concediendo la calidad de autores a las personas que colaboraron e inventaron su aportación a la puesta en escena. ${ }^{49}$

En este punto se debe considerar que la obra escenográfica, una vez culminada, es tan obra como cuando se encuentra en un diseño o en un boceto, por lo que carece de sentido proteger a los planos, bocetos, dibujos, etc., como obras bajo derechos de autor y no proteger la obra escenográfica una vez construida. La obra escenográfica como un todo jurídicamente no tiene mayor diferencia que el resto de las obras como un cuadro, por ejemplo. Ambos requieren de la creatividad y de la personalidad del autor y son plasmados en un soporte material, solo que mientras el soporte del cuadro es el lienzo, de la escenografía es el espacio escénico. Como señala Bercovitz ${ }^{50}$ con base en el caso de España, la escenografía podría encuadrarse dentro de una obra plástica. De igual manera, la ley italiana hace referencia expresa a la escenografía dentro de las demás obras plásticas.

Bajo este escenario, no se podría negar al escenógrafo la condición y la protección como autor. ${ }^{51}$ Podría incluso suceder que algunas de las piezas presentes en una escena se conviertan -más tarde, y bajo otro tipo de circunstancias- en obras autónomas y separadas de la escena, como sucede con algunas de las obras creadas por grandes artistas en la escena, como Joan Miró, Picasso, etc. Este tipo de obras podrían ser en lo posterior obras en sí mismas, protegibles de forma individual sin guardar relación con la obra escénica en colaboración para la que fueron creadas. Podrían incluso ser explotadas de forma independiente, atendiendo siempre a la limitación que ello no signifique un perjuicio a la explotación común de la obra, según analizamos en los casos anteriores.

Pese a que lo ideal para considerar a los escenógrafos como autores sería incluir a la escenografía en sí misma como una obra original en nuestra legislación -como en el derecho portugués-, la alternativa actual es enmarcarla dentro del ámbito de

48. Luiz Francisco Rebello, "El director de escena en el entorno jurídico europeo", en Jornadas sobre los derechos intelectuales del director de escena, ed. por Aisge (Madrid: Reus, 2001), 36.

49. Luis Felipe Ragel Sánchez, El contrato de representación teatral, Colección de propiedad intelectual (Madrid: Reus, 2003), 87.

50. Rodrigo Bercovitz Rodríguez-Cano, Comentarios a la Ley de Propiedad Intelectual, 2. a ed. (Madrid: Tecnos, 1997), 176.

51. Castellote, "Reconocimiento y protección de los derechos de autor en las escenografías", 159. 
protección conferido a las demás obra artísticas de tipo plástico o arquitectónico. ${ }^{52}$ Como bien ha señalado el Tribunal de Justicia de la CAN: "a los efectos de su tutela, la obra artística, científica o literaria, susceptible de reproducción o divulgación, debe ser una creación original. Por tanto, la protección no depende del mérito de la obra o de su destino". ${ }^{53}$ Por lo tanto, es preciso determinar su originalidad partiendo del nivel de creatividad y la impronta personal que deja el escenógrafo en la misma (pues sí puede suceder que el escenógrafo sea un técnico que se limita a ejecutar instrucciones impartidas por otros autores, sin libertad creadora).

\section{CONCLUSIONES}

1. La propiedad intelectual, mediante el derecho de autor y derechos conexos, ofrece las herramientas necesarias para la correcta y suficiente protección de las artes escénicas y de todos sus participantes y elementos creativos. Sin embargo, la forma de aplicación de estas herramientas no es lo suficientemente clara, dejando abierta la posibilidad de coartar la protección a ciertos autores cuyas obras reúnen los requisitos necesarios para ser susceptibles de protección bajo el derecho de autor.

2. Los derechos conexos garantizan cierto nivel de protección a los artistas, intérpretes y ejecutantes, menor al del derecho de autor. Por lo tanto, este régimen debe aplicarse únicamente a quienes realizan una actuación, interpretación o ejecución de la obra original y no realizan un trabajo creativo suficiente susceptible de protección por el derecho de autor. En caso de duda, se debería favorecer al creador y concederle la protección por el derecho de autor.

3. Se deberá analizar cada elemento creativo de forma separada para determinar si pueden llegar a constituir una obra protegible por el derecho de autor en sí

52. Tribunal de Justicia de la Comunidad Andina, Proceso 102-IP-2010, 14 de octubre de 2010: "se puede decir que se incluyen en el concepto de obras plásticas o artes plásticas, la cual engloba manifestaciones creativas muy distintas, en tanto que se parte de un concepto basado en la expresión a través de la forma y el color que se da a materias preexistentes. De acuerdo al Manual de propiedad intelectual de Rodrigo Bercovitz Rodríguez-Cano, '(...) se trata de un concepto - el de las obras plásticas- que incluye realidades tan dispares como la pintura y el dibujo, la escultura, la impresión gráfica original, los tapices y tejidos, la arquitectura, el urbanismo, los proyectos de ingeniería, los bocetos y ensayos, la escultura y pintura monumental en grandes dimensiones, la jardinería y composiciones florales, la decoración de interiores; las obras plásticas para el espectáculo (escenarios, vestuario, máscaras, escenografía y cuadros vivos), los cómics y personajes plásticos, los dibujos animados y la obra plástica audiovisual, elementos plásticos incluidos en los videojuegos, el artesanado, el arte aplicado, signos tipográficos, logotipos, etc.' (Rodrigo Bercovitz Rodríguez-Cano, Manual de propiedad intelectual, 3. ${ }^{\mathrm{a}}$ ed. [Valencia: Tirant lo Blanch, 2006], 67)".

53. Tribunal de Justicia de la Comunidad Andina, Proceso 044-IP-2013, 16 de julio de 2013, 23. 
mismas, como sucede en el caso del director de escena, cuando la escenificación sea propia y presente un grado de originalidad suficiente. Para ello, deberá poderse identificar y separar del resto de elementos de la obra escénica común y alcanzar los requisitos de protección antes analizados.

\section{BIBLIOGRAFÍA}

Bercovitz, Germán. Obra plástica y derechos patrimoniales de su autor. Madrid: Tecnos, 1997.

Bercovitz Rodríguez-Cano, Rodrigo. Comentarios a la Ley de Propiedad Intelectual. 2. ${ }^{a}$ ed. Madrid: Tecnos, 1997.

—. Manual de propiedad intelectual. 4. ${ }^{\mathrm{a}}$ ed. Valencia: Tirant lo Blanch, 2009.

Caballero Leal, José Luis. Derecho de autor para autores. México D. F.: Cerlalc / Libraria / Fondo de Cultura Económica, 2004.

Canaval Palacios, Juan Pablo. Manual de propiedad intelectual. Bogotá: Universidad del Rosario, 2008.

Castellote, Ruth. "Reconocimiento y protección de los derechos de autor en las escenografías". Revista Icade, n. 78 (2009): 145-60.

Comunidad Andina. Decisión 351. Régimen Común sobre Derecho de Autor y Derechos Conexos, 17 de diciembre de 1993. 〈http://www.comunidadandina.org/StaticFiles/DocOf/ DEC351.pdf .

Delgado Porras, Antonio. "Propiedad intelectual, derecho de autor y derechos conexos (afines) al de autor: nociones generales". En Derechos de autor y derechos afines al de autor, editado por Antonio Delgado Porras, 1: 265-92. Madrid: Instituto de Derecho de Autor, 2007.

España, Tribunal Supremo. "Sentencia". n. ${ }^{\circ} 778 / 2012$ (ROJ: STS 8998/2012), 27 de diciembre de 2012.

Gómez García, Manuel. Diccionario Akal de teatro. Madrid: Akal, 1998.

Mata y Martín, Ricardo. "Repercusiones del sistema normativo de la Unión Europea sobre la configuración de los delitos relativos a la propiedad industrial". En La aplicación privada del derecho de la competencia, editado por Luis Antonio Velasco San Pedro, Carmen Alonso Ledesma, Marina Echebarría Sáenz, Carmen Herrero Suárez y Javier Gutiérrez Gilsanz, 881-900. Valladolid: Lex Nova, 2011.

Moscoso del Prado, Adriana, y Jaume Colomer Vallicrosa, editores. Guía legal y financiera de las artes escénicas en España. Madrid: Instituto de Derecho de Autor, 2012.

Naciones Unidas. Convención de Roma sobre la protección de los artistas intérpretes o ejecutantes, los productores de fonogramas y los organismos de radiodifusión, 26 de octubre de 1961. 〈https://wipolex.wipo.int/es/treaties/textdetails/12656〉.

Ragel Sánchez, Luis Felipe. El contrato de representación teatral. Colección de Propiedad Intelectual. Madrid: Reus, 2003. 
Rebello, Luiz Francisco. "El director de escena en el entorno jurídico europeo”. En Jornadas sobre los derechos intelectuales del director de escena, editado por Aisge. Madrid: Reus, 2001.

Rengifo García, Ernesto, y Universidad Externado de Colombia. Propiedad intelectual: el moderno derecho de autor. Bogotá: Universidad Externado de Colombia, 1996.

Rogel Vide, Carlos, y Eduardo Serrano Gómez. Manual de derecho de autor. Madrid: Reus, 2008.

Soler Benito, Cristina. Artes escénicas y derechos de autor. Madrid: Reus, 2016.

Tribunal de Justicia de la Comunidad Andina. Interpretación Prejudicial, Proceso 39-IP-99, 1 de diciembre de 1999.

-. Proceso 102-IP-2010, 14 de octubre de 2010.

- Proceso 044-IP-2013, 16 de julio de 2013.

—. Proceso 225-IP-2015, Interpretación prejudicial, 23 de junio de 2016.

Vega Jaramillo, Alfredo. Manual de derecho de autor. Bogotá: Dirección Nacional de Derecho de Autor, 2010. 